\title{
Autoeficacia, estado emocional y autorregulación del aprendizaje en el estudiantado universitario durante la pandemia por COVID-19
}

Self-efficacy, emotional state and self-regulated learning in university students during COVID-19 pandemic

\section{Volumen 21, Número 3 \\ Setiembre - Diciembre}

pp. 1-24

\author{
Martha Leticia Gaeta González \\ Laura Gaeta González \\ María del Socorro Rodríguez Guardado
}

\section{Citar este documento según modelo APA}

Gaeta González, Martha Leticia., Gaeta González, Laura. y Rodríguez Guardado, María del Socorro. (2021). Autoeficacia, estado emocional y autorregulación del aprendizaje en el estudiantado universitario durante la pandemia por COVID-19. Revista Actualidades Investigativas en Educación, 21(3), 1-24. Doi. 10.15517/aie.v21i3.46280 


\title{
Autoeficacia, estado emocional y autorregulación del aprendizaje en el estudiantado universitario durante la pandemia por COVID-19
}

Self-efficacy, emotional state and self-regulated learning in university students during COVID19 pandemic

\author{
Martha Leticia Gaeta González 1 \\ Laura Gaeta González ${ }^{2}$ \\ María del Socorro Rodríguez Guardado ${ }^{3}$
}

Resumen: La pandemia por COVID-19 ha incidido fuertemente en todos los ámbitos de la sociedad, incluido el educativo. En el nivel universitario, la instrucción en línea ha generado diversos desafíos en el estudiantado para gestionar sus recursos personales y alcanzar los objetivos académicos. Desde un enfoque sociocognitivo, se realizó un estudio cuantitativo que tuvo como objetivos analizar la relación entre la autoeficacia, el estado emocional y la autorregulación del aprendizaje en el estudiantado universitario y contrastar su variación en función del género y del período académico durante el confinamiento a causa de la pandemia por COVID-19. Participaron 1665 personas procedentes de distintas universidades en México, quienes contestaron un cuestionario en línea entre junio y agosto de 2020. Los análisis de regresión indicaron que la autoeficacia para manejar situaciones estresantes, junto con emociones de desesperación, miedo y esperanza, inciden positivamente en la autorregulación del aprendizaje, mientras que el enojo lo hace negativamente. Las mujeres indicaron mayores puntajes en miedo, gratitud y compasión, así como en autorregulación del aprendizaje. El estudiantado de posgrado reportó tranquilidad, esperanza y gratitud con mayor frecuencia. Por su parte, el grupo de licenciatura de los últimos semestres $\left(7^{\circ}-10^{\circ}\right)$ indicó enojo, miedo y desinterés con mayor frecuencia y el menor nivel de autoeficacia y autorregulación del aprendizaje respecto a los de períodos académicos iniciales e intermedios. A partir de estos datos, es necesario promover acciones educativas que ayuden a la población universitaria a potenciar sus capacidades personales para influir en el entorno de cara al logro académico, por medio de una toma de conciencia de las dificultades que pueden limitar su aprendizaje y con un atento control de su cognición, estado emocional y comportamiento durante y después del confinamiento.

Palabras clave: pandemia, afectividad, aprendizaje en línea, enseñanza superior

Abstract: The COVID-19 pandemic has had a strong impact on all areas of society, including education. At the university level, online instruction has generated several challenges for students to manage their personal resources and achieve academic goals. From a socio-cognitive perspective, this study aims to analyze the relationship between self-efficacy, emotional state, and self-regulated learning in university students and contrast its variation according to gender and academic term during COVID-19 pandemic confinement. Participants were 1665 people from different Mexican universities who answered an online questionnaire between June and August 2020. Regression analysis indicated that self-efficacy to cope with stressful situations and emotions of despair, fear, and hope, positively affect self-regulated learning, while anger does it negatively. Women indicated more significant levels of fear, gratitude, compassion, and self-regulated learning. Postgraduate students reported tranquility, hope, and gratitude with the most significant frequency. On the other hand, the undergraduate students' group from the last semesters (7th-10th) indicated anger, fear and disinterest more frequently and the lowest level of self-efficacy and self-regulated learning, compared to students from initial and intermediate academic periods. From these data, it is necessary to promote actions that support university students in enhancing their capacities to improve their academic achievement by awareness of the difficulties that can limit their learning and careful control of their cognition, emotional state, and behavior during and after confinement.

Keywords: pandemics, emotions, online learning, higher education

\footnotetext{
${ }^{1}$ Docente de la Universidad Popular Autónoma del Estado de Puebla (UPAEP), Puebla, México. Dirección electrónica: marthaleticia.gaeta@upaep.mx ORCID: http://orcid.org/0000-0003-1710-217x

2 Docente de la Universidad Popular Autónoma del Estado de Puebla (UPAEP), Puebla, México. Dirección electrónica: laura.gaeta@upaep.mx ORCID: https://orcid.org/0000-0001-5493-9636

${ }^{3}$ Docente de la Universidad Popular Autónoma del Estado de Puebla (UPAEP), Puebla, México. Dirección electrónica: mariadelsocorro.rodriguez@upaep.mx ORCID: https://orcid.org/0000-0002-1575-2403
}

Artículo recibido: 18 de marzo, 2021

Enviado a corrección: 14 de junio, 2021

Aprobado: 16 de agosto, 2021 


\section{Introducción}

La pandemia originada por el coronavirus SARS-CoV-2, que genera la enfermedad COVID-19, si bien no ha sido la primera de este siglo ha afectado la salud y la vida de millones de personas a nivel mundial en solo unos pocos meses. Antes del primer brote en Wuhan, China, en diciembre del 2019, tanto el virus como la enfermedad eran totalmente desconocidos. Dada la rápida propagación del virus, la OMS declaró a la enfermedad como una emergencia de salud pública. Hasta el mes de noviembre de 2020 había cerca de 50 millones de personas infectadas en el mundo (WHO, 2020). Por lo que esta insólita situación ha incidido fuertemente en todos los ámbitos de la sociedad, incluido el educativo.

En México, la suspensión de clases presenciales en todos los niveles educativos y, cuando ha sido posible su impartición en la modalidad virtual, desde finales de marzo de 2020 (Sánchez, 2020), constituye una medida para reducir la propagación del virus entre la población. En el nivel universitario, las distintas instituciones educativas han implementado diversas acciones para la instrucción en línea, no obstante, este cambio tan repentino ha generado diversos desafíos para el estudiantado.

Estudios recientes (Rosario-Rodríguez, González-Rivera, Cruz-Santos y RodríguezRíos, 2020; Sánchez-Mendiola et al., 2020) indican que la nueva modalidad de enseñanza en línea durante el confinamiento en los hogares ha generado problemáticas en el alumnado relacionadas con estresores por sobrecarga de tareas, mala implementación de los cursos en línea, evaluaciones, poca flexibilidad y seguimiento personalizado del equipo docente, entre otros. Esto se suma a los estresores asociados al riesgo de contagio y a las problemáticas socioeconómicas familiares. La investigación realizada por Rosario-Rodríguez et al. (2020) pone de manifiesto que el balance entre la vida familiar, laboral y académica de la población estudiantil se ha visto afectado negativamente y alrededor del $90 \%$ ha aumentado sus niveles de estrés y ansiedad.

Ante este escenario, es razonable pensar que el estado emocional y la forma en que el estudiantado universitario mexicano se ha involucrado en el proceso de aprendizaje se han visto afectados. De ahí que resulta relevante indagar sobre la forma en que esta población ha puesto en marcha sus recursos cognitivos, motivacionales y afectivos de manera eficaz (autorregulación del aprendizaje), para persistir en sus estudios ante las dificultades y el estrés que involucra el aprendizaje remoto en este entorno de confinamiento por la pandemia.

El impacto emocional y la capacidad percibida para afrontar el estrés (autoeficacia), así como los procesos de autorregulación del aprendizaje durante el confinamiento por COVID-19 
también podrían presentar diferencias en función del género y de la edad. Esto debido a que, como se ha evidenciado en estudios previos, las mujeres universitarias son más vulnerables a presentar estrés (Cabanach, González y Freire, 2009) y ansiedad (Gutiérrez, Lobos y Chacón, 2020), y optan principalmente por la búsqueda de apoyo para afrontar estas respuestas, mientras que los varones recurren principalmente a estrategias de reevaluación positiva y planificación (Cabanach, Fariña, Freire, González y Ferradás, 2013). Por su parte, las personas de 18 a 23 años, que corresponde a la etapa universitaria, han evidenciado mayores niveles de ansiedad durante el confinamiento por la pandemia (Gutiérrez, 2020).

Asimismo, investigaciones en el ámbito educativo han reportado diferencias significativas en autoeficacia para el logro académico en función del género, en favor de los varones (Domínguez-Lara y Fernández-Arata, 2019). Sin embargo, en otros casos (Schnell, Ringeisen, Raufelder y Rohrmann, 2015) no se han hallado diferencias significativas de esta variable entre hombres y mujeres. Además, se ha mostrado que la autoeficacia percibida por el alumnado universitario presenta una mejora significativa a mediano plazo, conforme se avanza en los estudios. Así, se han identificado diferencias en el nivel de autoeficacia según el periodo académico que cursa el alumnado (Del Rosal y Bermejo, 2017). Estos hallazgos son consistentes en general con los resultados de otros estudios (Piergiovanni y Depaula, 2018) que han encontrado creencias más positivas sobre el propio desempeño académico en el grupo de estudiantes de mayor edad.

A partir de lo abordado previamente, el presente estudio tuvo como objetivos analizar la relación entre la autoeficacia, el estado emocional y la autorregulación del aprendizaje en el estudiantado universitario y contrastar su variación en función del género y del periodo académico durante el confinamiento por COVID-19.

\section{Referentes teóricos}

Al analizar los modelos de estudio más significativos sobre la autorregulación del aprendizaje, desde la perspectiva socio-cognitiva, se observa, en propuestas como las de Pintrich y Schunk (2006) y Zimmerman $(1989,2008)$, el supuesto de que las y los estudiantes son sujetos activos que construyen su propio proceso de aprendizaje, por lo que pueden controlar y regular potencialmente ciertos aspectos de su cognición, de su motivación-afecto y de su comportamiento, así como, en alguna medida, del contexto. Estos autores consideran que existe no solo algún tipo de criterio que ayuda al alumnado a decidir si el proceso de 
regulación requiere ajustes, sino que este proceso puede transferirse a distintas situaciones a partir de fases cíclicas de activación autorregulatoria (Panadero y Alonso-Tapia, 2014): planeamiento, ejecución y auto-reflexión. Desde este enfoque, el desarrollo del aprendizaje autorregulado se relaciona con factores de la persona (cognitivos, emocionales y motivacionales) y del medio ambiente, que operan de manera continua e interdependiente.

En el contexto descrito cobra especial relevancia la autorregulación del aprendizaje debido a que articula la conciencia del propio pensamiento, es decir, permite al alumnado observar y gestionar sus motivaciones y afectos, así como las conductas para aprender, (Crispín, Caudillo, Doria y Esquivel, 2011) al incidir en sus metas personales y en su sentido de autoeficacia asociada a aprendizajes más efectivos (Delgado, Martínez, Rodríguez y Escortell, 2019; Panadero y Alonso-Tapia, 2014; Zambrano-Matamala, Díaz-Mujica, PérezVillalobos y Rojas-Díaz, 2020). Tal como plantea Bandura (1993), las habilidades de autorregulación no tienen sentido si el estudiantado no es capaz de involucrarse de manera persistente ante las dificultades, distracciones y/o estrés.

Así, la autorregulación del aprendizaje constituye "el proceso mediante el cual las personas activan y sostienen cogniciones, sentimientos y comportamientos que se orientan sistemáticamente hacia la consecución de sus metas" (Zimmerman, 1989, p. 142). Por lo que se considera un proceso fundamental que permite a la población estudiantil ser consciente tanto de sus fortalezas como de sus debilidades académicas y desarrollar actividades de planeamiento, supervisión y monitoreo para el logro de sus objetivos de manera contextualizada (Zimmerman, 2008; Gaeta, 2020).

Como señalan Torrano, Fuentes y Soria (2017), existe cierto consenso respecto al perfil del estudiantado autorregulado; caracterizado por su capacidad de identificar en qué contextos y de qué forma aplicarán sus conocimientos, pudiendo vincular el trabajo actual con el futuro. Estos estudiantes se enfocan en el progreso personal, planteándose metas de aprendizaje, además de mostrar disposición por participar en clase y por aplicar distintas estrategias encaminadas a mantener la concentración y el esfuerzo durante la realización de las tareas académicas.

Con base en estos planteamientos, podemos señalar que conseguir una autorregulación eficaz depende tanto de la autoconfianza para manejar el ambiente como para gestionar los propios recursos de cara al logro de las actividades académicas. Las emociones también tienen un papel importante en este proceso, pues configuran la interacción entre el sentido de 
autoeficacia y el comportamiento autorregulado, aspectos que aún no se han aclarado en la población universitaria durante la pandemia por COVID-19.

La incertidumbre por la crisis sanitaria, como han indicado varios investigadores (Johnson, Saletti-Cuesta y Tumas, 2020; Sandín, Valiente, García-Escalera y Chorot, 2020) ha generado diversas afectaciones emocionales en la población universitaria, como preocupación, miedo y angustia. Sin embargo, el confinamiento también ha favorecido algunas experiencias personales positivas, como sentimientos de responsabilidad, cuidado y valoración de otras personas. Además, como señala la investigación de Rosario-Rodríguez et al. (2020), la ansiedad generada por el seguimiento de las actividades en línea y las demandas académicas ha sido mayor para muchas personas que la ocasionada por la propia pandemia.

Como menciona Rigo (2020), aprender en línea durante el confinamiento ha implicado un reto para el estudiantado universitario al tener que organizar lugares, tiempos y recursos tecnológicos compartidos, e incluso lograr una adecuada concentración ante diversos distractores. En este mismo sentido, Sansone, Smith, Thoman y MacNamara (2012) señalan que, en los contextos en línea, las interacciones sociales relativamente restringidas provocan desafíos adicionales para la gestión de las emociones, de tal manera que el estudiantado puede presentar dificultad al expresarse, mientras que el personal docente puede enfrentar problemas en la interpretación de las dudas y emociones para promover el aprendizaje con esta modalidad.

Sin embargo, para muchos estudiantes, el compromiso con su proceso formativo al asumir autonomía para gestionar su aprendizaje, en su manifestación cognitiva, afectiva y conductual, ha permitido superar las dificultades de contar o no con una buena conexión a Internet o la complejidad propia de las plataformas virtuales. Así, esta situación extraordinaria ha demandado que este grupo de estudiantes utilice todos los recursos personales para adecuarse a las nuevas condiciones y para persistir en sus metas académicas. Ello implica que evalúen, en primer lugar, sus capacidades para manejar de manera eficaz las diversas situaciones estresantes, que les permita involucrarse en su aprendizaje académico con éxito.

Teniendo esto en consideración, en el presente estudio se incluyó el constructo de autoeficacia, ya que refleja la confianza personal para llevar a cabo un comportamiento en situaciones desafiantes, en este caso, el continuar con los estudios de manera eficaz durante el confinamiento en casa por COVID-19. De acuerdo con la teoría social cognitiva, la autoeficacia es un factor cognitivo que permite ejercer control sobre los propios pensamientos y comportamientos (Bandura, 1993, 2000). Se refiere a las creencias personales sobre la 
capacidad para llevar a cabo ciertas acciones u obtener los resultados esperados en un contexto determinado (Bandura, 1993; Schunk y Ertmer, 2000) o a la valoración de la capacidad para enfrentar situaciones amenazantes o estresantes (Bandura, 1993).

Los aportes de Bandura (2000) en este campo señalan que la autoeficacia influye en otros aspectos determinantes del comportamiento, como son las metas, y en la percepción de los obstáculos presentes en el entorno social. De ahí que las creencias de autoeficacia constituyen un factor fundamental para el sentido de logro del estudiantado y, por tanto, son un importante predictor del comportamiento y éxito académico (Cleary y Kitsantas, 2017). Como han mostrado los hallazgos de estudios recientes sobre el tema (Wang et al., 2020), cuando las personas presentan altos niveles de autoeficacia tienen más confianza para enfrentar las circunstancias desafiantes generadas por la pandemia del COVID-19. Asimismo, este constructo tiene un efecto protector ante el estrés generado por las actividades académicas (Cabanach, Valle, Rodríguez, Piñeiro y González, 2010; Gutiérrez-García y Landeros-Velázquez, 2018) y se encuentra positivamente asociado al bienestar emocional de la población estudiantil universitaria (Rodríguez et al., 2018).

Como plantean Gaskill y Woolfolk (2002), la percepción de autoeficacia y el aprendizaje autorregulado requieren una serie similar de procesos cognitivos y metacognitivos, incluyendo la capacidad de establecer metas, monitorear el progreso y la autoevaluación. Así, la percepción de autoeficacia es una variable sustancial en los procesos de autorregulación del aprendizaje (Bandura, 1993; Cerezo et al., 2019; Covarrubias-Apablaza, Acosta-Antognoni y Mendoza-Lira, 2019). Todo ello es fundamental para que cada estudiante pueda aplicar de forma consciente estrategias de aprendizaje, planeando y monitoreando sus esfuerzos con miras a mantener su desempeño. Por lo que la autoeficacia y el aprendizaje autorregulado se vuelven variables relevantes en el marco de la enseñanza en línea y en condiciones de confinamiento, lo cual podría implicar un alto nivel de estrés.

\section{Metodología}

\subsection{Enfoque}

Se trata de un estudio cuantitativo no experimental, desarrollado por vía de un diseño transversal de una sola etapa, con un alcance correlacional. 


\subsection{Participantes}

Se recurrió a un muestreo incidental, según el cual se invitó al estudiantado de distintas universidades mexicanas a participar de manera voluntaria. La muestra final quedó integrada por 1665 personas (71.3\% mujeres), con edad media de 23.68 ( $D E=7.3)$. Los participantes cursaban estudios de licenciatura (87.3\%) y posgrado $(12.7 \%)$ en instituciones privadas $(72.3 \%)$ y públicas $(27.7 \%)$ del país. El grupo de estudiantes de licenciatura, en su mayoría, se encontraba cursando entre el $7^{\circ}$ y $10^{\circ}$ periodo académico $(41.1 \%)$, seguido por los que cursaban entre el $4^{\circ}$ y $6^{\circ}$ período (35.4\%), y entre el $1^{\circ}$ y $3^{\circ}$ período (23.6\%). Respecto al programa de estudios, con base en la Clasificación Mexicana de Programas de Estudio por Campos de Formación Académica de 2011 (Instituto Nacional de Estadística y Geografía [INEGI], 2012), el 36.4\% se encontraba estudiando en programas del área de la salud; el 19.3\% de Ciencias Sociales, Administración y Derecho; el 15.8\% de Educación; el 6.2\% de Ciencias Naturales y Exactas; el 5.1\% de Ingenierías, Manufactura y Construcción; el 2.9\% de Artes y Humanidades; el 1.1\% de Agronomía y Veterinaria, y el resto de participantes (13.4\%) no especificó el programa de estudios.

En cuanto a las condiciones de vivienda, el $44 \%$ de participantes se encontraba viviendo en los estados del centro del país, el $32.5 \%$ en el noroeste, el $18.9 \%$ en el sur-sureste y un menor porcentaje en el occidente $(3.5 \%)$ y noreste $(0.8 \%)$. En su mayoría $(70.6 \%)$ reportaron vivir en un entorno urbano, el $18.4 \%$ en un entorno semiurbano y el $11.1 \%$ en un entorno rural. Casi en su totalidad se encontraban viviendo con familiares (95.9\%), el 1.6\% vivía con conocidos y el $2.5 \%$ vivía solo. La mayoría (77.3\%) reportó contar con un espacio personal para el estudio y con conexión a internet (93.4\%), así como computadora y otros dispositivos electrónicos (83.2\%), mientras que el $11.7 \%$ refirió contar solo con tableta y/o celular, y el 5.1\% solo con computadora.

\subsection{Instrumento}

Para la obtención de la información se diseñó un cuestionario que se administró durante los meses de junio a agosto de 2020 durante el confinamiento en casa por COVID-19. Dicho cuestionario permitió indagar sobre cuatro aspectos: sociodemográficos, autoeficacia, estado emocional y autorregulación del aprendizaje, a partir de instrumentos validados por sus autores, que se sometieron al juicio de dos investigadores expertos en el tema y a análisis de fiabilidad. A continuación, se describen sus características: 
a) Datos sociodemográficos. En esta sección se indaga el género y la edad de la muestra, así como los datos académicos y las condiciones de vivienda durante el confinamiento, presentados anteriormente.

b) Autoeficacia. Se evaluó usando la adaptación española de la Self-efficacy Scale (Baessler y Schwarzer, 1996; Sanjuán-Suárez, Pérez-García y Bermúdez-Moreno, 2000). Este instrumento mide el sentimiento de competencia personal para manejar de manera eficaz diversas situaciones estresantes, por medio de una escala de respuesta likert de 5 puntos. Para el presente estudio se usaron 5 ítems (de los 10 originales). El instrumento adaptado presenta un índice de fiabilidad $\alpha=0.88$.

c) Estado emocional. Las personas participantes seleccionaron de una lista de 15 emociones: alegría, compasión, esperanza, gratitud, tranquilidad, aburrimiento, ansiedad/preocupación, confusión, desesperación, desinterés, enojo, frustración, miedo, soledad, tristeza (Bisquerra, 2009; Pekrun, Goetz y Perry, 2005), aquellas que habían experimentado durante el confinamiento, haciendo uso de una escala tipo likert de 5 puntos. La escala total presenta un índice de fiabilidad $\alpha=0.83$.

d) Autorregulación del aprendizaje. Se evaluó a través del Self-Regulation Formative Questionnaire (Gaumer-Erickson y Noonan, 2018). El instrumento, conformado por 22 ítems, con una escala de respuesta likert de 5 puntos, mide el nivel de competencia percibido en los cuatro componentes esenciales de la autorregulación: a) Planificación (5 ítems; $\alpha=0.76$ ); b) Monitoreo del progreso (6 ítems; $\alpha=0.77$ ); c) Control de cambios realizados (6 ítems; $\alpha=0.76$ ); d) Reflexión sobre los resultados (5 ítems; $\alpha=0.75$ ). El instrumento total presenta un índice de fiabilidad de $\alpha=0.92$.

\subsection{Procedimiento y análisis de datos}

El cuestionario fue distribuido en línea (formulario Google Forms), a través de correo electrónico institucional, redes sociales y contactos profesionales con el propósito de llegar a un gran número de personas. Los datos de la muestra se protegieron en todo momento, bajo estricta confidencialidad, con base en la Declaración de Helsinki y la aprobación del Comité de Ética Universitario.

De 1719 cuestionarios se eliminaron 54 por presentar una gran cantidad de datos ausentes y/o valores atípicos. La estructura interna de los instrumentos, así como la normalidad y la linealidad de los datos fue revisada previo a su análisis. Se efectuaron análisis descriptivos (de centralidad y frecuencia) e inferenciales: análisis bivariados no paramétricos 
(correlación de Spearman), análisis de regresión por pasos sucesivos hacia adelante (incluyendo la valoración global del ajuste y la validación de los residuos) y comparativos no paramétricos por género ( $U$ de Mann-Whitney), y periodo académico (Kruskal Wallis). Se asumió un nivel de significancia estadística del 0.05 para la aceptación o rechazo de las hipótesis estadísticas. Los análisis estadísticos se realizaron a través del programa SPSS v.22.

\section{Resultados}

\subsection{Relación entre estado emocional, autoeficacia y autorregulación del aprendizaje del alumnado}

La Tabla 1 muestra los resultados de correlación entre el estado emocional, la autoeficacia y la autorregulación del aprendizaje del alumnado universitario por componente. La autoeficacia se asocia positivamente con la tranquilidad $\left(r_{s}=.27 ; p<.01\right)$, la esperanza $\left(r_{s}\right.$ $=.23 ; p<.01)$, la gratitud $\left(r_{s}=.23 ; p<.01\right)$, la alegría $\left(r_{s}=.28 ; p<.01\right)$ y la compasión $\left(r_{s}=.13\right.$; $p<.01)$. Con menor fuerza, la autoeficacia se relaciona negativamente con la soledad $\left(r_{s}=-\right.$ $.11 ; p<.01)$, el enojo $\left(r_{s}=-.11 ; p<.01\right)$, la frustración $\left(r_{s}=-.10 ; p<.05\right)$, el aburrimiento $\left(r_{s}=\right.$ -.08; $p<.01)$, el miedo $\left(r_{s}=-.06 ; p<.01\right)$, la confusión $\left(r_{s}=-.07 ; p<.01\right)$, la tristeza $\left(r_{s}=-.08\right.$; $p<.01)$, la ansiedad $\left(r_{s}=-.09 ; p<.01\right)$, el desinterés $\left(r_{s}=-.08 ; p<.01\right)$ y la desesperación $\left(r_{s}\right.$ $=-.11 ; p<.01)$.

Por su parte, la autorregulación del aprendizaje se asocia positivamente con la tranquilidad $\left(r_{s}=.20 ; p<.01\right)$, la esperanza $\left(r_{s}=.23 ; p<.01\right)$, la gratitud $\left(r_{s}=.21 ; p<.01\right)$, la alegría $\left(r_{s}=.22 ; p<.01\right)$ y la compasión $\left(r_{s}=.14 ; p<.01\right)$. Asimismo, se observó una relación positiva, aunque de menor intensidad, con el miedo $\left(r_{s}=.07 ; p<.01\right)$. Cada una de las fases del proceso de autorregulación (planeamiento, monitoreo, control, reflexión) se correlaciona con emociones consideradas positivas (compasión, tranquilidad, esperanza, gratitud y alegría). Además, el miedo también presenta una relación positiva, aunque de baja intensidad, con la autorregulación total $\left(r_{s}=.07 ; p<.01\right)$ y con las fases de reflexión $\left(r_{s}=.07 ; p<.01\right)$ y control $\left(r_{s}=.07 ; p<.01\right)$. 
Tabla 1. Correlación entre estado emocional, autoeficacia y autorregulación del aprendizaje del alumnado universitario por componente, México, junio-

\begin{tabular}{|c|c|c|c|c|c|c|c|c|c|c|c|c|c|c|c|c|c|c|c|c|}
\hline & 1 & 2 & 3 & 4 & 5 & 6 & 7 & 8 & 0 & 11 & 11 & 11 & 12 & & 15 & 10 & 17 & 10 & 10 & 8 \\
\hline \multicolumn{21}{|l|}{ 1.Compasión } \\
\hline 2.Tranquilidad & $.28^{* *}$ & & & & & & & & & & & & & & & & & & & \\
\hline 3.Esperanza & $.34^{* *}$ & $.44^{* *}$ & & & & & & & & & & & & & & & & & & \\
\hline 4.Gratitud & $.43^{* *}$ & $.33^{* *}$ & $.50^{* *}$ & & & & & & & & & & & & & & & & & \\
\hline 5.Alegría & $.28^{* *}$ & $.45^{* *}$ & $.47^{* *}$ & $.46^{* *}$ & & & & & & & & & & & & & & & & \\
\hline 6.Soledad & $.11^{* *}$ & $-.20^{* *}$ & $-.10^{* *}$ & .03 & $.13^{*}$ & & & & & & & & & & & & & & & \\
\hline 7.Enojo & $.13^{* *}$ & $-.22^{* *}$ & -.01 & $.10^{* *}$ & $-.05^{*}$ & $.42^{* *}$ & & & & & & & & & & & & & & \\
\hline 8.Frustración & $.11^{* *}$ & $-.31^{* \star}$ & $-.05^{*}$ & $.09^{* *}$ & $.11^{--}$ & $.48^{* *}$ & $.70^{* *}$ & & & & & & & & & & & & & \\
\hline 9.Aburrimiento & $.06^{*}$ & $-.13^{* *}$ & -.04 & .05 & -.01 & $.39^{* *}$ & $.40^{\star *}$ & $.43^{* *}$ & & & & & & & & & & & & \\
\hline 10.Miedo & $.21^{* *}$ & $-.21^{\star \star}$ & $.08^{* *}$ & $.16^{* *}$ & -.04 & $.36^{* *}$ & $.40^{* *}$ & $.44^{* *}$ & $.31^{* *}$ & & & & & & & & & & & \\
\hline 11.Confusión & $.20^{* *}$ & $-.21^{* *}$ & .02 & $.16^{* *}$ & -.03 & $.41^{* *}$ & $.48^{* *}$ & $.55^{* *}$ & $.33^{* *}$ & $.60^{* *}$ & & & & & & & & & & \\
\hline 12. Tristeza & $.16^{* *}$ & $-.25^{* \star}$ & -.03 & $.08^{* *}$ & $.11^{-}$ & $.55^{* *}$ & $.54^{\star *}$ & $.60^{* *}$ & $.43^{* *}$ & $.54^{* *}$ & $.58^{* *}$ & & & & & & & & & \\
\hline 13.Ansiedad & $.13^{* *}$ & $-.29^{* *}$ & -.03 & $.11^{* *}$ & $.08^{* *}$ & $.46^{* *}$ & $.54^{* *}$ & $.65^{* *}$ & $.37^{* *}$ & $.54^{* *}$ & $.58^{* *}$ & $.70^{* *}$ & & & & & & & & \\
\hline 14.Desinterés & .01 & $-.11^{* *}$ & $-.05^{*}$ & -.01 & $-.05^{*}$ & $.33^{* *}$ & $.39^{* *}$ & $.39^{* *}$ & $.31^{* *}$ & $.31^{* *}$ & $.38^{* *}$ & $.43^{* *}$ & $.42^{* *}$ & & & & & & & \\
\hline 15.Desesperación & $.09^{* *}$ & $-.29^{* *}$ & $-.06^{*}$ & .04 & $.07^{-}$ & $.43^{* *}$ & $.54^{* *}$ & $.62^{* *}$ & $.47^{* *}$ & $.50^{* *}$ & $.55^{* *}$ & $.61^{* *}$ & $.67^{* *}$ & $.43^{* *}$ & & & & & & \\
\hline 16.Autoeficacia & $.13^{* *}$ & $.27^{* *}$ & $.23^{* *}$ & $.23^{* *}$ & $.28^{* *}$ & $.11^{-}$ & $.11^{-}$ & $.10^{-}$ & $.08^{\star *}$ & $-.06^{*}$ & $.07^{* *}$ & $.08^{* *}$ & $.09^{-}$ & $.08^{* *}$ & $.11^{-}$ & & & & & \\
\hline 17.Planeamiento & $.11^{* *}$ & $.21^{* *}$ & $.22^{* *}$ & $.14^{* *}$ & $.1^{8^{* *}}$ & $.08^{-}$ & $-.09^{* *}$ & $.08^{-}$ & $.06^{* *}$ & .03 & -.03 & -.04 & -.02 & $.07^{-}$ & -.04 & $.46^{* *}$ & & & & \\
\hline 18.Monitoreo & $.12^{* *}$ & $.19^{* *}$ & $.19^{* *}$ & $.21^{* *}$ & $.19^{* *}$ & -.05 & $-.05^{*}$ & -.03 & -.01 & .05 & -.00 & -.01 & .01 & -.05 & .00 & $.53^{* *}$ & $.69^{* *}$ & & & \\
\hline 19.Control & $.080^{* *}$ & $.128^{* \star}$ & $.131^{* *}$ & $.13^{* *}$ & $.14^{* *}$ & -.00 & -.04 & .00 & .02 & $.07^{* *}$ & .03 & .05 & $.05^{*}$ & -.01 & $.06^{*}$ & $.50^{* *}$ & $.56^{* *}$ & $.63^{* *}$ & & \\
\hline 20.Reflexión & $.155^{* *}$ & $.168^{* *}$ & $.242^{* *}$ & $.2^{3^{3 *}}$ & $.22^{* *}$ & -.04 & -.04 & -.03 & -.03 & $.07^{* *}$ & .02 & .00 & .03 & $-.06^{*}$ & .01 & $.59^{* *}$ & $.59^{* *}$ & $.64^{* *}$ & $.66^{* *}$ & \\
\hline 21.Autoregulac. & $.137^{\star *}$ & $.203^{* *}$ & $.229^{* *}$ & $.21^{* *}$ & $.22^{* *}$ & $-.05^{*}$ & $-.06^{* *}$ & $.041^{-}$ & -.02 & $.07^{* *}$ & .01 & -.00 & .02 & $-.05^{*}$ & .01 & $.61^{* *}$ & $.83^{* *}$ & $.88^{* *}$ & $.84^{* *}$ & $.85^{* *}$ \\
\hline
\end{tabular}




\subsection{Incidencia del estado emocional y la autoeficacia en la autorregulación del aprendizaje del alumnado}

En la Tabla 2 se presentan los resultados de la regresión realizada con la finalidad de analizar la incidencia de la autoeficacia y el estado emocional en la autorregulación del aprendizaje total, así como en cada una de sus dimensiones. Se puede observar que la autoeficacia $(\beta=.59 ; p<.001)$, el miedo $(\beta=.09 ; p<.001)$ y la desesperación $(\beta=.10 ; p<$ $.001)$ inciden positivamente en la autorregulación del aprendizaje.

Con respecto a cada una de las fases de la autorregulación, la autoeficacia incide de manera positiva en todas ellas $(\beta=.42 ; p<.001 ; \beta=.50 ; p<.001 ; \beta=.50 ; p<.001 ; \beta=.57$; $p<.001)$. Por su parte, la esperanza $(\beta=.11 ; p<.001)$, la tranquilidad $(\beta=.06 ; p<.05)$ y el miedo $(\beta=.09 ; p<.001)$ inciden de forma positiva en el planeamiento. La gratitud $(\beta=.07 ; p$ $<.05)$ y el miedo $(\beta=.09 ; p<.001)$ inciden positivamente en la fase de monitoreo. El miedo es la única emoción que muestra una incidencia significativa en la fase de control $(\beta=.11 ; p<$ .001). Tanto la esperanza $(\beta=.08 ; p<.001)$ como el miedo $(\beta=.10 ; p<.001)$ inciden positivamente en la fase de reflexión.

Tabla 2. Incidencia del estado emocional y de la autoeficacia en la autorregulación del aprendizaje del alumnado universitario según el análisis de regresión jerárquico, México, junioagosto de 2020

\begin{tabular}{|c|c|c|c|c|c|}
\hline & B & Error estándar & $\begin{array}{c}\text { B } \\
\text { estandarizado }\end{array}$ & $\mathrm{t}$ & $P$ \\
\hline \multicolumn{6}{|c|}{ Autorregulación del aprendizaje } \\
\hline Constante & $39.85^{\circ}$ & 1.66 & & 24.06 & .001 \\
\hline Esperanza & .67 & .26 & .06 & 2.53 & .012 \\
\hline Alegría & .01 & .29 & .00 & .031 & .976 \\
\hline Gratitud & .27 & .25 & .03 & 1.04 & .296 \\
\hline Tranquilidad & .41 & .28 & .04 & 1.46 & .146 \\
\hline Miedo & .93 & .24 & .09 & 3.86 & .001 \\
\hline Enojo & -.77 & .28 & -.07 & -2.74 & .006 \\
\hline $\begin{array}{l}\text { Desesperaci } \\
\text { ón }\end{array}$ & .97 & .26 & .10 & 3.79 & .001 \\
\hline Desinterés & -.42 & .22 & -.04 & -1.88 & .060 \\
\hline Autoeficacia & 1.79 & .06 & .59 & 28.74 & .001 \\
\hline \multicolumn{6}{|c|}{$\left[F_{(10,1649)}=106.37 ; p<.001\right] R^{2}$ ajustado $=0.39$} \\
\hline \multicolumn{6}{|l|}{ Planeamiento } \\
\hline Constante & 9.74 & .51 & & 18.93 & .001 \\
\hline Compasión & .03 & .07 & .01 & .32 & .748 \\
\hline Tranquilidad & 19 & .09 & .06 & 2.25 & .024 \\
\hline Esperanza & .32 & .08 & .11 & 3.88 & .001 \\
\hline Gratitud & -.11 & .08 & -.04 & -1.34 & .180 \\
\hline Alegría & -.02 & .09 & -.01 & -.22 & .826 \\
\hline Soledad & -.04 & .07 & -.01 & -.53 & .594 \\
\hline Enojo & -.15 & .08 & -.05 & -1.76 & .078 \\
\hline Miedo & .26 & .07 & .09 & 3.65 & .001 \\
\hline Desinterés & -.08 & .07 & -.03 & -1.18 & .240 \\
\hline Autoeficacia & .35 & .02 & .42 & 18.43 & .001 \\
\hline \multicolumn{6}{|c|}{$\left[\mathrm{F}_{(10,1649)}=50.69 ; p<.001\right] \mathrm{R}^{2}$ ajustado $=0.23$} \\
\hline
\end{tabular}




\begin{tabular}{|c|c|c|c|c|c|}
\hline \multicolumn{4}{|l|}{ Monitoreo } & & .001 \\
\hline Compasión & -.02 & .09 & -.00 & -.18 & .859 \\
\hline Tranquilidad & .11 & .10 & .03 & 1.13 & .260 \\
\hline Esperanza & .06 & .10 & .02 & .63 & .531 \\
\hline Gratitud & .24 & .09 & .07 & 2.58 & .010 \\
\hline Alegría & .02 & .10 & .01 & .18 & .855 \\
\hline Soledad & .01 & .08 & .00 & .09 & .927 \\
\hline Enojo & -.09 & .10 & -.02 & -.91 & .364 \\
\hline Miedo & .29 & .08 & .09 & 3.48 & .001 \\
\hline Desinterés & -.06 & .08 & -.02 & -.79 & .431 \\
\hline Autoeficacia & .51 & .02 & .50 & 22.74 & .001 \\
\hline \multicolumn{6}{|c|}{$\left[\mathrm{F}_{(10,1649)}=68.88 ; p<.001\right] \mathrm{R}^{2}$ ajustado $=0.29$} \\
\hline \multicolumn{6}{|l|}{ Control } \\
\hline (Constante) & 12.41 & .54 & & 22.84 & .001 \\
\hline Compasión & -.05 & .08 & -.02 & -.63 & .532 \\
\hline Tranquilidad & .05 & .09 & .01 & .53 & .599 \\
\hline Esperanza & .03 & .09 & .01 & .31 & .753 \\
\hline Gratitud & -.00 & .09 & -.00 & -.03 & .979 \\
\hline Alegría & .01 & .09 & .00 & .06 & .950 \\
\hline Soledad & .10 & .08 & .03 & 1.33 & .185 \\
\hline Enojo & -.12 & .09 & -.04 & -1.37 & .172 \\
\hline Miedo & .34 & .08 & .11 & 4.41 & .001 \\
\hline Desinterés & .01 & .07 & .00 & 18 & .855 \\
\hline Autoeficacia & .45 & .02 & .50 & 22.03 & .001 \\
\hline \multicolumn{6}{|c|}{$\left[\mathrm{F}_{(10,1649)}=57.46 ; p<.001\right] \mathrm{R}^{2}$ ajustado $=0.25$} \\
\hline \multicolumn{6}{|l|}{ Reflexión } \\
\hline Constante & 7.89 & .47 & & 16.70 & .001 \\
\hline Compasión & .06 & .07 & .02 & .88 & .380 \\
\hline Tranquilidad & -.12 & .08 & -.04 & -1.49 & .136 \\
\hline Esperanza & .24 & .08 & .08 & 3.21 & .001 \\
\hline Gratitud & .13 & .07 & .04 & 1.78 & .076 \\
\hline Alegría & .07 & .08 & .02 & .85 & .395 \\
\hline Soledad & .03 & .07 & .01 & .47 & .638 \\
\hline Enojo & -.08 & .08 & -.02 & -1.04 & .300 \\
\hline Miedo & .29 & .07 & .10 & 4.39 & .001 \\
\hline Desinterés & -.11 & .06 & -.04 & -1.74 & .082 \\
\hline Autoeficacia & .48 & .02 & .57 & 27.18 & .001 \\
\hline \multicolumn{6}{|c|}{$\left[\mathrm{F}_{(10,1649)}=98.93 ; p<.001\right] \mathrm{R}^{2}$ ajustado $=0.37$} \\
\hline
\end{tabular}

Nota: Se aplicó el método de pasos sucesivos hacia adelante

Fuente: Elaboración propia, 2020

\subsection{Comparativos del estado emocional autoeficacia y autorregulación del} aprendizaje del alumnado según el género y el periodo académico

En la Tabla 3 se muestran los comparativos respecto a la autoeficacia, el estado emocional y la autorregulación del aprendizaje según el género y el periodo académico que cursa el estudiantado. Los comparativos por género indicaron que la autoeficacia $(z=2.4, p<$ .05) la tranquilidad $(z=6.6, p<.001)$ y el enojo $(z=6.7, p<.001)$ fueron más frecuentes en los varones. Por su parte, las mujeres indicaron emociones socialmente positivas, como la compasión $(z=4.4, p<.001)$ y la gratitud $(z=2.2, p<.05)$ con más frecuencia. Aunque, emociones como el miedo $(z=8.5, p<.001)$ y el desinterés $(z=2.0, p<.05)$ también fueron más frecuentes en las mujeres. Por otro lado, las mujeres reflejaron, en promedio, una mayor 
autorregulación del aprendizaje total $(z=3.6, p<.001)$, así como en tres de sus dimensiones monitoreo $(z=2.5, p<.05)$, control $(z=4.6, p<.001)$ y reflexión $(z=3.7, p<.001)$.

En cuanto a los comparativos por periodo académico (Tabla 3), el grupo de estudiantes de posgrado reportó tranquilidad $\left(x^{2}=11.0, p<.05\right)$, esperanza $\left(x^{2}=15.0, p<.01\right)$ y gratitud $\left(x^{2}=11.7, p<.01\right)$ con mayor frecuencia. También fueron quienes indicaron soledad en menor grado $\left(x^{2}=19.2, p<.001\right)$. Por su parte, el estudiantado de $7^{\circ}-10^{\circ}$, seguidos por los de $4^{\circ}-6^{\circ}$ indicaron presentar enojo $\left(x^{2}=29.4, p<.001\right)$ y miedo $\left(x^{2}=11.6, p<.01\right)$ con mayor frecuencia. El grupo de estudiantes de $7^{\circ}-10^{\circ}$ reportó desinterés $\left(x^{2}=37.5, p<.001\right)$ de manera más frecuente, además de autoeficacia $\left(x^{2}=17.2, p<.01\right)$ en un menor porcentaje y autorregulación total en sus cuatro dimensiones (planeamiento $x^{2}=17.9, p<.001$; monitoreo $x^{2}=10.7, p<.05 ;$ control $x^{2}=22.8, p<.001$ y reflexión $x^{2}=10.3, p<.01$ ).

Tabla 3. Estado emocional, autoeficacia y autorregulación del aprendizaje del alumnado universitario según el género y el periodo académico, México, junio-agosto de 2020

\begin{tabular}{|c|c|c|c|c|c|c|c|c|c|}
\hline & \multirow{2}{*}{$\begin{array}{c}\text { Muestra } \\
\text { total }\end{array}$} & \multicolumn{2}{|c|}{ Género } & \multirow[b]{3}{*}{$\mathbf{Z}$} & \multicolumn{4}{|c|}{$\begin{array}{l}\text { Periodo académico (en } \\
\text { licenciatura/Posgrado) }\end{array}$} & \multirow[b]{3}{*}{$\mathbf{X}^{2}$} \\
\hline & & Mujeres & $\begin{array}{c}\text { Hombre } \\
\text { s }\end{array}$ & & $\begin{array}{l}1^{\circ}-3^{\circ} \\
(1)\end{array}$ & $\begin{array}{l}4^{0}-6^{\circ} \\
(2)\end{array}$ & $\begin{array}{l}7^{\circ}-10^{\circ} \\
(3)\end{array}$ & $\begin{array}{l}\text { Posgrado } \\
\text { (4) }\end{array}$ & \\
\hline & $\begin{array}{l}\text { Media } \\
\text { (DE) }\end{array}$ & $\begin{array}{l}\text { Media } \\
\text { (DE) }\end{array}$ & $\begin{array}{l}\text { Media } \\
\text { (DE) }\end{array}$ & & $\begin{array}{l}\text { Media } \\
\text { (DE) }\end{array}$ & $\begin{array}{l}\text { Media } \\
\text { (DE) }\end{array}$ & $\begin{array}{l}\text { Media } \\
\text { (DE) }\end{array}$ & $\begin{array}{l}\text { Media } \\
\text { (DE) }\end{array}$ & \\
\hline Compasión & $\begin{array}{c}3.1 \\
(1.1)\end{array}$ & $\begin{array}{c}3.2 \\
(1.1)\end{array}$ & $\begin{array}{c}3.0 \\
(1.2)\end{array}$ & $4.4^{* * *}$ & $\begin{array}{c}3.2 \\
(1.2)\end{array}$ & $\begin{array}{c}3.1 \\
(1.1)\end{array}$ & $\begin{array}{c}3.1 \\
(1.1)\end{array}$ & $\begin{array}{c}3.2 \\
(1.1)\end{array}$ & 4.1 \\
\hline Tranquilidad & $\begin{array}{c}3.3 \\
(1.0)\end{array}$ & $\begin{array}{c}3.2 \\
(1.0)\end{array}$ & $\begin{array}{l}3.6 \\
(1.1)\end{array}$ & $6.6^{* \star *}$ & $\begin{array}{c}3.4 \\
(1.1)\end{array}$ & $\begin{array}{l}3.2 \\
(1.1)\end{array}$ & $\begin{array}{c}3.3 \\
(1.0)\end{array}$ & $\begin{array}{l}3.5 \\
(1.0)\end{array}$ & $11.0^{*}$ \\
\hline Esperanza & $\begin{array}{c}3.4 \\
(1.1)\end{array}$ & $\begin{array}{c}3.4 \\
(1.1)\end{array}$ & $\begin{array}{c}3.4 \\
(1.2)\end{array}$ & 1.7 & $\begin{array}{c}3.4 \\
(1.2)\end{array}$ & $\begin{array}{l}3.3 \\
(1.1)\end{array}$ & $\begin{array}{c}3.4 \\
(1.0)\end{array}$ & $\begin{array}{l}3.6 \\
(1.1)\end{array}$ & $15.0^{\star *}$ \\
\hline Gratitud & $\begin{array}{c}3.7 \\
(1.1)\end{array}$ & $\begin{array}{l}3.7 \\
(1.1)\end{array}$ & $\begin{array}{c}3.5 \\
(1.2)\end{array}$ & $2.2^{*}$ & $\begin{array}{c}3.5 \\
(1.3)\end{array}$ & $\begin{array}{l}3.6 \\
(1.2)\end{array}$ & $\begin{array}{c}3.7 \\
(1.1)\end{array}$ & $\begin{array}{c}3.9 \\
(1.0)\end{array}$ & $11.7^{* *}$ \\
\hline Alegría & $\begin{array}{c}3.5 \\
(1.0)\end{array}$ & $\begin{array}{c}3.5 \\
(1.0)\end{array}$ & $\begin{array}{c}3.5 \\
(1.1)\end{array}$ & 1.9 & $\begin{array}{c}3.5 \\
(1.1)\end{array}$ & $\begin{array}{l}3.5 \\
(1.0)\end{array}$ & $\begin{array}{c}3.5 \\
(1.0)\end{array}$ & $\begin{array}{c}3.5 \\
(1.0)\end{array}$ & .25 \\
\hline Soledad & $\begin{array}{c}2.6 \\
(1.2)\end{array}$ & $\begin{array}{c}2.6 \\
(1.1)\end{array}$ & $\begin{array}{c}2.5 \\
(1.3)\end{array}$ & 1.9 & $\begin{array}{c}2.6 \\
(1.2)\end{array}$ & $\begin{array}{c}2.6 \\
(1.2)\end{array}$ & $\begin{array}{c}2.6 \\
(1.1)\end{array}$ & $\begin{array}{l}2.3 \\
(1.2)\end{array}$ & $19.2^{* * *}$ \\
\hline Enojo & $\begin{array}{c}2.9 \\
(1.0)\end{array}$ & $\begin{array}{c}3.0 \\
(1.0)\end{array}$ & $\begin{array}{l}2.6 \\
(1.1)\end{array}$ & $6.7^{* * *}$ & $\begin{array}{c}2.7 \\
(1.1)\end{array}$ & $\begin{array}{c}2.9 \\
(1.0)\end{array}$ & $\begin{array}{c}3.0 \\
(1.0)\end{array}$ & $\begin{array}{l}2.6 \\
(1.0)\end{array}$ & $29.4^{* * *}$ \\
\hline Miedo & $\begin{array}{c}2.7 \\
(1.2)\end{array}$ & $\begin{array}{l}2.8 \\
(1.1)\end{array}$ & $\begin{array}{c}2.3 \\
(1.2)\end{array}$ & $8.5^{\star \star \star}$ & $\begin{array}{c}2.5 \\
(1.2)\end{array}$ & $\begin{array}{l}2.7 \\
(1.2)\end{array}$ & $\begin{array}{c}2.8 \\
(1.2)\end{array}$ & $\begin{array}{c}2.6 \\
(1.2)\end{array}$ & $11.6^{* *}$ \\
\hline Desinterés & $\begin{array}{c}2.5 \\
(1.2)\end{array}$ & $\begin{array}{c}2.5 \\
(1.2)\end{array}$ & $\begin{array}{c}2.4 \\
(1.2)\end{array}$ & $2.0^{*}$ & $\begin{array}{c}2.3 \\
(1.1)\end{array}$ & $\begin{array}{c}2.6 \\
(1.2)\end{array}$ & $\begin{array}{c}2.6 \\
(1.2)\end{array}$ & $\begin{array}{c}2.1 \\
(1.1)\end{array}$ & $37.5^{\star \star \star}$ \\
\hline Autoeficacia & $\begin{array}{l}19.7 \\
(4.0)\end{array}$ & $\begin{array}{l}19.5 \\
(3.9)\end{array}$ & $\begin{array}{l}20.0 \\
(4.1)\end{array}$ & $2.4^{*}$ & $\begin{array}{l}19.8 \\
(4.0)\end{array}$ & $\begin{array}{l}19.6 \\
(4.0)\end{array}$ & $\begin{array}{l}19.3 \\
(4.0)\end{array}$ & $\begin{array}{l}20.6 \\
(3.6)\end{array}$ & $17.2^{\star *}$ \\
\hline Planeamiento & $\begin{array}{l}18.0 \\
(3.3)\end{array}$ & $\begin{array}{l}18.2 \\
(3.2)\end{array}$ & $\begin{array}{l}17.8 \\
(3.5)\end{array}$ & 1.7 & $\begin{array}{l}18.2 \\
(3.5)\end{array}$ & $\begin{array}{l}18.2 \\
(3.4)\end{array}$ & $\begin{array}{l}17.6 \\
(3.3)\end{array}$ & $\begin{array}{l}18.6 \\
(2.8)\end{array}$ & $17.9^{\star \star \star}$ \\
\hline Monitoreo & $\begin{array}{l}22.5 \\
(4.0)\end{array}$ & $\begin{array}{l}22.7 \\
(4.0)\end{array}$ & $\begin{array}{l}22.2 \\
(4.1)\end{array}$ & $2.5^{\star}$ & $\begin{array}{l}22.7 \\
(4.2)\end{array}$ & $\begin{array}{l}22.8 \\
(4.1)\end{array}$ & $\begin{array}{l}22.2 \\
(3.9)\end{array}$ & $\begin{array}{l}22.6 \\
(3.9)\end{array}$ & $10.7^{*}$ \\
\hline Control & $\begin{array}{l}22.2 \\
(3.6)\end{array}$ & $\begin{array}{l}22.4 \\
(3.6)\end{array}$ & $\begin{array}{l}21.6 \\
(3.5)\end{array}$ & $4.6^{\star * \star}$ & $\begin{array}{l}22.5 \\
(3.6)\end{array}$ & $\begin{array}{l}22.5 \\
(3.7)\end{array}$ & $\begin{array}{l}21.9 \\
(3.6)\end{array}$ & $\begin{array}{l}21.6 \\
(2.8)\end{array}$ & $22.8^{\star * *}$ \\
\hline Reflexión & $\begin{array}{l}19.0 \\
(3.4)\end{array}$ & $\begin{array}{l}19.2 \\
(3.4)\end{array}$ & $\begin{array}{l}18.6 \\
(3.4)\end{array}$ & $3.7^{\star \star *}$ & $\begin{array}{l}19.3 \\
(3.5)\end{array}$ & $\begin{array}{l}19.3 \\
(3.5)\end{array}$ & $\begin{array}{l}18.7 \\
(3.4)\end{array}$ & $\begin{array}{l}18.9 \\
(2.9)\end{array}$ & $13.0^{* *}$ \\
\hline $\begin{array}{l}\text { Autorregulac. } \\
\text { del aprendizaje }\end{array}$ & $\begin{array}{c}81.8 \\
(12.2)\end{array}$ & $\begin{array}{l}82.5 \\
(12.0)\end{array}$ & $\begin{array}{c}80.1 \\
(12.4)\end{array}$ & $3.6^{* * *}$ & $\begin{array}{c}82.7 \\
(12.6)\end{array}$ & $\begin{array}{c}82.8 \\
(12.8)\end{array}$ & $\begin{array}{c}80.4 \\
(11.9)\end{array}$ & $\begin{array}{l}81.6 \\
(10.5)\end{array}$ & $17.4^{\star *}$ \\
\hline
\end{tabular}

${ }^{*} p<.05 ;{ }^{* *} p<.01 ;{ }^{* * *} p<.001$

Fuente: Elaboración propia, 2020 


\subsection{Discusión}

Con base en los objetivos del presente estudio: analizar la relación entre la autoeficacia, el estado emocional y la autorregulación del aprendizaje en el estudiantado universitario y contrastar su variación en función del género y periodo académico durante el confinamiento por COVID-19, a continuación, se discuten los principales hallazgos.

En general, se constata el importante papel de la autoeficacia percibida en los procesos de ajuste del estudiantado universitario durante el confinamiento en casa por COVID-19. De manera específica, se observó una asociación lineal entre la autoeficacia y las emociones positivas (compasión, tranquilidad, esperanza, gratitud, alegría). Además, se advirtió una relación inversa entre la autoeficacia y las emociones negativas (soledad, desesperación, enojo, frustración, aburrimiento, miedo, confusión, tristeza, ansiedad, desinterés). Si bien, la fuerza de estas relaciones es baja, en concordancia con otros estudios (Wang et al., 2020), podemos decir que cuando el alumnado tiene altos niveles de autoeficacia, confía en sus capacidades para hacer frente a la situación adversa por la pandemia. De esta forma, como muestran los resultados de este estudio, las personas tienden a presentar emociones placenteras y de tipo empático, al tiempo que experimentar estas emociones puede fortalecer su autoeficacia.

Con los matices propios del presente estudio, las creencias de autoeficacia del estudiantado reflejan la capacidad percibida para hacer frente a distintas situaciones estresantes y de generar estados emocionales positivos que inciden en su aprendizaje durante el confinamiento por la pandemia. Esto se relaciona con los hallazgos de otros estudios previos (Delgado et al., 2019; Rodríguez et al., 2018) en cuanto a la contribución de altos niveles de eficacia en la generación de sentimientos de serenidad y esperanza ante la dificultad, lo que también potencializa la gratitud y la compasión. De igual forma, la desesperación tiende a disminuir cuando las personas se consideran capaces de enfrentar sus deberes académicos ante la situación adversa que se esté presentando. Por lo tanto, la autoeficacia se convierte en un factor protector del estrés (Cabanach et al., 2010) y se vincula con mejores resultados de salud (Wang et al., 2020), así como con el empleo de conductas promotoras de aprendizaje.

Así, la autorregulación del aprendizaje presenta una relación lineal con todas las emociones positivas (compasión, tranquilidad, esperanza, gratitud, alegría), así como una relación inversa con la soledad, el enojo y el desinterés. Estos resultados dan cuenta de que cuando el alumnado modula su pensamiento, afecto y comportamiento disminuye sus estados de soledad, enojo, aumentando su interés en el aprendizaje. Asimismo, en concordancia con 
Moreno-Rodríguez y Vargas-Merino (2019), emociones como la alegría se asocian positivamente con las distintas dimensiones del aprendizaje de las personas universitarias.

Un hallazgo interesante es que, aunque con poca fuerza, el miedo se relaciona de manera positiva con la autorregulación del aprendizaje, particularmente en las fases de control y reflexión. Este resultado contrasta con el de Moreno-Rodríguez y Vargas-Merino (2019), quienes reportan una relación negativa entre el miedo y el aprendizaje. Sin embargo, es importante recordar que el miedo, como una emoción primaria (Bisquerra, 2009) que surge como respuesta a las amenazas -en este caso, asociadas a la situación insólita de pandemiatiene la función de alertar de peligros, pudiendo ayudar a la persona a identificar cuando algo no está bien y a anticipar una fatalidad si no se actúa en consecuencia, por lo que le permite utilizar procesos cognitivos a favor de la autorregulación de su aprendizaje. Cabe destacar que en esta muestra los niveles de miedo son moderados, lo cual puede contribuir a que el alumnado active sus recursos personales en favor de sus metas académicas; el miedo en una intensidad y/o frecuencia mayor podría generar un bloqueo emocional, aturdimiento o inmovilización ante determinadas acciones.

Al analizar la incidencia de la autoeficacia percibida y del estado emocional en la autorregulación del aprendizaje se encontró que la autoeficacia junto con la esperanza, el miedo y la desesperación tienden a favorecer los procesos de autorregulación de forma positiva. Estos resultados corroboran que cuando las personas se sienten capaces de afrontar las situaciones estresantes con un sentido esperanzador, vinculado a su vez, al miedo y a la desesperación ante la situación insólita que están viviendo, contribuye a anticipar consecuencias negativas de no actuar, en este caso, de implicarse en el estudio.

Respecto a las distintas fases de la autorregulación del aprendizaje, se encontró que la autoeficacia incide de manera positiva en todas ellas. En consonancia con la literatura (Santoya-Montes, Garcés-Prettel y Tezón-Boutureira, 2018; Schunk y Ertmer, 2000), este constructo constituye un factor clave para lograr organizar y ejecutar las actividades académicas propuestas que contribuyen a un óptimo desempeño. Asimismo, cuando se ha estudiado la autoeficacia de manera conjunta con el autoconcepto o el rendimiento académico ha resultado un sólido predictor de la vida académica de la población estudiantil, pues se ha constatado su relación con la motivación, el esfuerzo y la perseverancia (Pajares, 1996).

Por su parte, la esperanza, la tranquilidad y el miedo inciden positivamente en el planeamiento, mientras que la gratitud y el miedo lo hacen en la fase de monitoreo. El miedo es la única emoción que incide en la fase de control. Finalmente, tanto la esperanza como el 
miedo inciden de manera positiva en la fase de reflexión. Lo anterior sugiere que al tener una visión positiva del futuro y tranquilidad, aunque con cierto temor, comprensible frente a la incertidumbre, el estudiantado puede establecer mejores estrategias para planear, mantener su esfuerzo y hacer un mejor uso de sus recursos para un óptimo aprendizaje.

Tal como refiere Rigo (2020), el aprendizaje virtual durante el confinamiento en casa por la pandemia ha sido desafiante para el estudiantado universitario, por lo que se requiere de mucha autonomía y compromiso con las metas que cada uno se propone y con el reto que implica el aprender de distinta manera. En su estudio, este autor reportó que a partir de la enseñanza remota por la pandemia, el grupo de estudiantes mostró compromiso con sus estudios, redobló su implicación, estableció metas personales y organizó sus tiempos y recursos con la dinámica familiar.

Al contrastar los resultados en función del género, destaca que las mujeres experimentaron más frecuentemente emociones de tipo empático, como compasión y gratitud, lo que puede reflejar que están más conscientes de su entorno y se ven afectadas por lo que pueda sucederles a otras personas durante la pandemia. Esto puede estar asociado también a que son ellas quienes reportan mayor miedo, a diferencia de los hombres, al estar más alertas de esta situación crítica. Este dato coincide con los resultados de otros estudios (Extremera, Durán y Rey, 2007) que reportan que las mujeres prestan mayor atención a las emociones que los varones, mientras que ellos refirieron una mayor capacidad para reparar sus estados emocionales.

Por su parte, aunque en principio podría parecer contradictorio, un mayor porcentaje de mujeres presentó desinterés, en comparación con los varones, esto podría atender a mecanismos protectores producto del desgaste emocional, lo que lleva en consecuencia a implicarse en menor medida en algunas situaciones o a no querer estar al tanto de todo lo que ocurre, para no abrumarse en demasía. En este sentido, como mencionan Moreno-Rodríguez y Vargas-Merino (2019), una causa importante del desinterés en ocasiones se debe a aspectos emocionales que, en este caso, están exacerbados.

En el caso de los varones, el enojo fue más frecuente que en las mujeres, lo cual podría ser en general un mecanismo de descarga frente a los cambios o a las frustraciones que pudieran acompañar al confinamiento, reportándose al final niveles significativamente más altos de tranquilidad respecto al género femenino. Esto también podría estar relacionado con procesos socializadores característicos de nuestra cultura, en donde la expresión de enojo se permite más a los hombres, pues, tal como refieren De la Cruz, Olarte y Rodríguez (2019) en 
México, los estudiantes varones siguen reproduciendo patrones comportamentales vinculados a la hegemonía masculina, y atendiendo a las prescripciones sociales vinculadas a la fortaleza, ausencia de emociones y sentimientos.

En cuanto a la autorregulación del aprendizaje, las mujeres reportaron en promedio mayores niveles en la autorregulación total y en tres de sus dimensiones -monitoreo, control y reflexión. Este resultado es coincidente en parte con lo encontrado por Zambrano-Matamala et al. (2020), quienes observaron diferencias significativas en la dimensión organización del entorno, con niveles más altos en las mujeres. Por su parte, los varones reportaron mayores niveles de autoeficacia que las mujeres, lo cual coincide con los hallazgos de Domínguez-Lara y Fernández-Arata (2019). Sin embargo, parece que el estado emocional de enojo que prevalece en ellos aminora su propensión a autorregular su aprendizaje.

Respecto a los comparativos por periodo académico, se encontró que el grupo de estudiantes de posgrado reportó tranquilidad, esperanza y gratitud con mayor frecuencia, y fueron quienes indicaron soledad en menor grado, lo cual puede estar relacionado con procesos madurativos. Por su parte, el grupo de estudiantes de licenciatura, particularmente de los últimos semestres $\left(7^{\circ}-10^{\circ}\right)$ indicó enojo, miedo y desinterés con mayor frecuencia y el menor porcentaje de autoeficacia y autorregulación del aprendizaje, respecto al estudiantado de periodos académicos iniciales e intermedios. Estos resultados, en general, contrastan con los hallazgos de Zambrano-Matamala et al. (2020), quienes encontraron en general puntuaciones más bajas en autoeficacia en universitarios de los primeros semestres. También, Piergiovanni y Depaula (2018) reportaron que el grupo de estudiantes de mayor edad, generalmente asociada a un mayor nivel académico, obtuvieron creencias más positivas sobre su propio desempeño académico. Por su parte, Domínguez-Lara y Fernández-Arata (2019) observaron que la autoeficacia académica percibida por los universitarios presenta una mejora significativa a mediano plazo. Sin embargo, otras investigaciones (Del Rosal y Bermejo, 2017) que contrastan el nivel de autoeficacia según el grado en el que se encuentran matriculadas las personas han encontrado resultados similares a los del presente estudio.

La respuesta negativa en el grupo de estudiantes próximos a graduarse podría estar relacionada con el hecho de que habitualmente en estas fases este grupo de estudiantes se ve en la necesidad de realizar prácticas profesionales, servicio social y tienen la expectativa de graduarse e insertarse al campo laboral y, en estas circunstancias de confinamiento, este tipo de actividades se han restringido de manera sustancial. 


\section{Conclusiones}

Consideramos que los presentes resultados aportan al conocimiento respecto del papel preponderante de la autoeficacia para enfrentar situaciones estresantes, como el aprendizaje en línea durante el confinamiento en casa por la pandemia del COVID-19. Además, pudimos constatar la incidencia positiva de la autoeficacia percibida para afrontar el estrés y de las emociones positivas en los procesos de autorregulación del aprendizaje del estudiantado universitario. Los datos obtenidos en esta investigación indicaron además que el género y la edad, generalmente asociada al nivel educativo, son factores diferenciadores en cuanto a los estados emocionales positivos, en este caso en favor de las mujeres y del grupo de estudiantes de posgrado, lo que también corrobora la repercusión de las emociones en los procesos de autorregulación del aprendizaje.

Por último, a partir de los hallazgos de este estudio, se considera necesario promover acciones que apoyen al estudiantado universitario a potenciar sus capacidades personales para influir en el entorno de cara al logro académico, por medio de una toma de conciencia de las dificultades que pueden impedir su aprendizaje y con un atento control de su cognición, estado emocional y comportamiento durante y post-confinamiento.

\subsection{Limitantes del estudio}

Teniendo en consideración las limitaciones de movilidad por el confinamiento durante la pandemia, la opción más viable para la obtención de datos fue el cuestionario en línea. Una limitante se relaciona con una mayor participación de mujeres, que de hombres, lo que plantea un sesgo en los resultados del estudio, al igual que la mayor participación de personas de universidades privadas, así como de zonas urbanas y del centro-sur del país, asociada en parte a una mayor conexión a internet. Sin embargo, el tamaño de la muestra se considera adecuado para los propósitos del estudio.

Sería importante realizar más estudios que pudieran dar mayor orientación sobre las problemáticas específicas que vive el estudiantado de universidades públicas y en las zonas semiurbana y rural, lo que puede dar pautas para establecer acciones específicas acordes con las necesidades de la población universitaria en los contextos en los que están viviendo el confinamiento. Asimismo, sería conveniente considerar la propuesta de un estudio longitudinal para analizar el comportamiento de las variables aquí estudiadas a medida en que las condiciones de confinamiento cambian. 


\section{Agradecimientos}

Al estudiantado universitario, por su participación voluntaria y desinteresada en el presente estudio.

\section{Referencias}

Baessler, Judith. y Schwarzer, Ralf. (1996). Evaluación de la autoeficacia: Adaptación española de la escala de Autoeficacia General. Ansiedad y Estrés, 2(1), 1-8. Recuperado de http://dialnet.unirioja.es/servlet/articulo?codigo=186652

Bandura, Albert. (1993). Perceived Self-Efficacy in Cognitive Development and Functioning. Educational Psychologist, 28(2), 117-148. doi https://doi.org/10.1207/s15326985ep2802 3

Bandura, Albert. (2000). Exercise of Human Agency through Collective Efficacy. Current Directions in Psychological Science, 9(3), 75-78. Recuperado de https://www.jstor.org/stable/20182630

Bisquerra, Rafael. (2009). Psychopedagogy of emotions. Madrid, España: Síntesis.

Cabanach, Ramón., Fariña, Francisca., Freire, Carlos., González, Patricia. y Ferradás, María del Mar. (2013). Diferencias en el afrontamiento del estrés en estudiantes universitarios hombres y mujeres. European Journal of Education and Psychology, 6(1), 19-32. Recuperado de https://www.redalyc.org/pdf/1293/129327497002.pdf

Cabanach, Ramón., González, Patricia. y Freire, Carlor. (2009). El afrontamiento del estrés en estudiantes de ciencias de la salud. Diferencias entre hombres y mujeres. Aula Abierta, 37(2), 3-10. Recuperado de https://dialnet.unirioja.es/servlet/articulo?codigo $=3088531$

Cabanach, Ramón., Valle, Antonio., Rodríguez, Susana., Piñeiro, Isabel. y González, Patricia. (2010). Las creencias motivacionales como factor protector del estrés en estudiantes universitarios. European Journal of Education and Psychology, 3(1), 75-87. Recuperado de https://www.redalyc.org/pdf/1293/129313736006.pdf

Cerezo, Rebeca., Fernández, Estrella., Amieiro, Natalia., Valle, Antonio., Rosário, Pedro. y Núñez, José Carlos. (2019). El papel mediador de la autoeficacia y la utilidad entre el conocimiento y el uso de estrategias de autorregulación del aprendizaje. Revista de Psicodidáctica, 24(1), 1-8. Doi https://doi.org/10.1016/j.psicoe.2018.09.001

Cleary, Tim. y Kitsantas, Anastasia. (2017). Motivation and self-regulated learning influences on middle school mathematics achievement. School Psychology Review, 46(1), 88-107. doi: https://doi.org/10.17105/SPR46-1.88-107

Covarrubias-Apablaza, Carmen., Acosta-Antognoni, Hady. y Mendoza-Lira, Michelle. (2019). Relación de Autorregulación del Aprendizaje y Autoeficacia General con las Metas Académicas de Estudiantes Universitarios. Formación Universitaria, 12(6), 103-114. doi: https://doi.org/10.4067/S0718-50062019000600103 
Crispín, María Luisa., Caudillo, Lourdes., Doria, María del Carmen. y Esquivel, Melisa. (2011). Aprendizaje Autónomo. En M. L. Crispín, Aprendizaje Autónomo: Orientaciones para la Docencia (pp. 49-65). Ciudad de México, México: Universidad Iberoamericana.

De la Cruz, Gustavo., Olarte, Carlos Arturo. y Rodríguez, Jannet. (2019). Entre golpes y empujones, la comunicación afectiva entre varones universitarios. Revista Electrónica de Investigación Educativa, 21(e11), $1-9 . \quad$ doi: https://doi.org/10.24320/redie.2019.21.e11.1887

Delgado, Beatriz., Martínez, María Carmen., Rodríguez, José Ramón. y Escortell, Raquel. (2019). La autoeficacia académica y la inteligencia emocional como factores asociados al éxito académico de los estudiantes universitarios. Revista Gestión de las Personas y Tecnología, 12(35). Recuperado de https://www.revistas.usach.cl/ojs/index.php/revistagpt/article/view/4003

Domínguez-Lara, Sergio. y Fernández-Arata, Manuel. (2019). Autoeficacia académica en estudiantes de Psicología de una universidad de Lima. Revista Electrónica de Investigación Educativa, 21(32). doi: https://doi.org/10.24320/redie.2019.21.e32.2014

Extremera, Natalio., Durán, María Auxiliadora. y Rey, Lourdes. (2007). Inteligencia emocional y su relación con los niveles de burnout, engagement y estrés en estudiantes universitarios. Revista de Educación, 44(342), 239-256. Recuperado de https://dialnet.unirioja.es/servlet/articulo?codigo $=2253635$

Gaeta, Martha Leticia. (2020). Autorregulación del aprendizaje. En V.G. Covarrubias (Comp.), Bases para la inducción y el desarrollo del pensamiento científico en la niñez y la preadolescencia (pp. 77-109). México: Concytep.

Gaskill, Pamela., y Woolfolk, Anita. (2002). Self-Efficacy and Self-Regulated Learning: The Dynamic Duo in School Performance. En J. Aronson (Ed.), Improving Academic Achievement: Impact of Psychological Factors on Education (pp. 185-208). San Diego, CA: Academic Press.

Gaumer-Erickson, Amy. y Noonan, Patricia. (2018). Self-regulation formative questionnaire. En The skills that matter: Teaching interpersonal and intrapersonal competencies in any classroom (pp. 177-178). Thousand Oaks, CA: Corwin.

Gutiérrez, José Ricardo., Lobos, Marlon Elías. y Chacón, Edgardo René. (2020). Síntomas de ansiedad por la COVID-19, como evidencia de afectación de salud mental en universitarios salvadoreños. $\quad$ Recuperado de http://repositorio.utec.edu.sv:8080/jspui/bitstream/11298/1171/3/112981171.pdf

Gutiérrez-García, Ana. y Landeros-Velázquez, María Gerarda. (2018). Autoeficacia académica y ansiedad, como incidente crítico, en mujeres y hombres universitarios. Revista Costarricense de Psicología, 37(1), 1-25. doi: https://doi.org/10.22544/rcps.v37i01.01

Instituto Nacional de Estadística y Geografía (INEGI). (2012). Clasificación Mexicana de Programas de Estudio por campos de Formación Académica 2011. Educación Superior y Media Superior. México: Instituto Nacional de Estadística y Geografía. Recuperado de https://www.copaes.org/documentos/Anexo-A-Clasificacion-Mexicana-de-Programasde-Estudio.pdf 
Johnson, María Cecilia., Saletti-Cuesta, Lorena. y Tumas, Natalia. (2020). Emociones, preocupaciones y reflexiones frente a la pandemia del COVID-19 en Argentina. Ciencia y Saúde Colectiva, 25(Supl. 1), 2447-2456. doi: https://doi.org/10.1590/1413$\underline{81232020256.1 .10472020}$

Moreno-Rodríguez, Rosa Ysabel. y Vargas-Merino, Jorge Alberto. (2019). La influencia de las emociones y la corporalidad en el aprendizaje de estudiantes universitarios. RIDE. Revista Iberoamericana para la Investigación y el Desarrollo Educativo, 9(18), 254-274. doi: https://doi.org/10.23913/ride.v9i18.423

Pajares, Frank. (1996). Self-Efficacy in academic settings. Review of Educational Research, 66(4), 543-578. Recuperado de https://www.uky.edu/ eushe2/Pajares/Pajares1996RER.pdf

Panadero, Ernesto. y Alonso-Tapia, Jesús. (2014). Teorías de autorregulación educativa: una comparación y reflexión teórica. Psicología Educativa, 20(1), 11-22. doi: https://doi.org/10.1016/j.pse.2014.05.002

Pekrun, Reinhard., Goetz, Thomas. y Perry, Raymond. (2005). Academic Emotions Questionnaire (AEQ). User's manual. Recuperado de https://es.scribd.com/doc/217451779/2005-AEQ-Manual

Piergiovanni, Lucia Florencia. y Depaula, Pablo Domingo. (2018). Descriptive Study of Selfefficacy and Stress Management among Argentinean University Students. Revista Mexicana de Investigación Educativa, 23(77), 413-432. Recuperado de http://www.scielo.org.mx/scielo.php?script=sci arttextypid=S1405$\underline{66662018000200413 y \operatorname{lng}=\text { esytlng=es }}$

Pintrich, Paul. y Schunk, Dale. (2006). Motivación en contextos educativos. Madrid, España: Prentice Hall.

Rigo, Daiana-Yamila. (2020). Percepciones del estudiantado argentino de nivel superior acerca del compromiso, clima del aula virtual y tendencias a futuro: entre posibilidades y limitaciones en tiempos de pandemia. Revista Innovaciones Educativas, 22(Especial), 143-161. doi: $\underline{\text { https://doi.org/10.22458/ie.v22iEspecial.3132 }}$

Rodríguez, Susana., Piñeiro, Isabel., Regueiro, Bibiana., Estévez, Iris., Valle, Antonio. y Núñez, José Carlos. (2018). Bienestar emocional de los estudiantes universitarios: el papel de la orientación a metas y las percepciones de control. Publicaciones, 48(1), 211224. doi: https://doi.org/10.30827/publicaciones.v48i1.7324

Del Rosal, Irene. y Bermejo, María Luisa. (2017). Autoeficacia en estudiantes universitarios: diferencias entre el grado de maestro en educación primaria y los grados en ciencias. Revista Internacional de Psicología del Desarrollo y la Educación, 1(1), 115-123. Recuperado de http://www.redalyc.org/articulo.oa?id=349852544012

Rosario-Rodríguez, Adam., González-Rivera, Juan Aníbal., Cruz-Santos, Andrés. y Rodríguez-Ríos, Luismiguel. (2020). Demandas tecnológicas, académicas y psicológicas en estudiantes universitarios durante la pandemia por COVID-19. Revista Caribeña de Psicología, 4(2), 176-185. doi: https://doi.org/10.37226/rcp.v4i2.4915 
Sánchez, Arturo. (2020, 27 de marzo). En reunión virtual, SEP afirma sobre acciones ante COVID-19. La Jornada. Recuperado de https://www.jornada.com.mx/ultimas/sociedad/2020/03/27/en-reunion-virtual-sepinforma-sobre-acciones-ante-covid-19-5271.html

Sánchez-Mendiola, Melchor., Martínez-Hernández, Ana Marìa del Pilar., Torres-Carrasco, Ruth., De Agüero-Servín, María de las Mercedes., Hernández-Romo, Alan Kristiàn., Benavides-Lara, Mario Alberto., Jaimes-Vergara, Carlos Alberto. y Rendón-Cazales, Víctor Jesús. (2020). Retos educativos durante la pandemia de CoviD-19: una encuesta a profesores de la UNAM [Ahead of print]. Revista Digital Universitaria (RDU). Recuperado de https://www.revista.unam.mx/prensa/retos-educativos-durantela-pandemia-de-covid-19-una-encuesta-a-profesores-de-la-unam/

Sandín, Bonifacio., Valiente, Rosa., García-Escalera, Julia. y Chorot, Paloma. (2020). Psychological impact of the COVID-19 pandemic: Negative and positive effects in Spanish people during the mandatory national quarantine. Revista de Psicopatología y Psicología Clínica, 25(1), 1-22. doi: https://doi.org/10.5944/rppc.27569

Sanjuán-Suárez, Pilar., Pérez-García, Ana María. y Bermúdez-Moreno, José. (2000). Escala de autoeficacia general: datos psicométricos de la adaptación para población española. Psicothema, 12(2), 509-513. Recuperado de http://www.psicothema.com/pdf/615.pdf

Sansone, Carol., Smith, Jessi., Thoman, Dustin. y MacNamara, Atara. (2012). Regulating interest when learning online: Potential motivation and performance trade-offs. Internet and Higher Education, 15(3), 141-149. doi: https://doi.org/10.1016/j.iheduc.2011.10.004

Santoya-Montes, Yanin., Garcés-Prettel, Miguel. y Tezón-Boutureira, Mariana. (2018). Las emociones en la vida universitaria: análisis de la relación entre autoconocimiento emocional y autorregulación emocional en adolescentes y jóvenes universitarios. Psicogente, 21(40), 422-439. doi: https://doi.org/10.17081/psico.21.40.3081

Schnell, Kerstin., Ringeisen, Tobias., Raufelder, Diana. y Rohrmann, Sonja. (2015). The impact of adolescents' self-efficacy and self-regulated goal attainment processes on school performance - Do gender and test anxiety matter? Learning and Individual Differences, 38, 90-98. doi: https://doi.org/10.1016/j.lindif.2014.12.008

Schunk, Dale. y Ertmer, Peggy. (2000). Self-Regulation and Academic Learning: Self-Efficacy Enhancing interventions. En M. Boekaerts, P. Pintrich y M. Zeidner (Eds.), Handbook of Self-Regulation (pp. 631-649). San Diego, CA: Academic Press.

Torrano, Fermín., Fuentes, Juan Luis. y Soria, María. (2017). Aprendizaje autorregulado: estado de la cuestión y retos psicopedagógicos. Perfiles Educativos, 39(156),160-173. doi: https://doi.org/10.22201/iisue.24486167e.2017.156.58290

Wang, Shengnan., Feng, Kai., Zhang, Ying., Liu, Jianan., Wang, Wei. y Li, Yongxin. (2020). Antecedents of Public Mental Health During the COVID-19 Pandemic: Mediation of Pandemic-Related Knowledge and Self-Efficacy and Moderation of Risk Level. Frontiers in Psychiatry, 11. doi: https://doi.org/10.3389/fpsyt.2020.567119 
World Health Organization [WHO]. (2020). COVID-19 weekly epidemiological update. Recuperado de https://apps.who.int/iris/handle/10665/336478

Zambrano-Matamala, Carolina., Díaz-Mujica, Alejandro., Pérez-Villalobos, María. y RojasDíaz, Dario. (2020). Análisis de estrategias de autorregulación en estudiantes de pedagogía de una universidad chilena. Formación Universitaria, 13(5), 223-232. doi: https://doi.org/10.4067/S0718-50062020000500223

Zimmerman, Barry. (1989). A Social Cognitive View of Self-Regulated Academic Learning. Journal of Educational Psychology, 81(3), 329-339. doi: https://doi.org/10.1037/0022$\underline{0663.81 .3 .329}$

Zimmerman, Barry. (2008). Investigating self-regulation and motivation: historical background, methodological developments, and future prospects. American Educational Research Journal, 45(1), 166-183. doi: https://doi.org/10.3102\%2F0002831207312909 
Revista indizada en
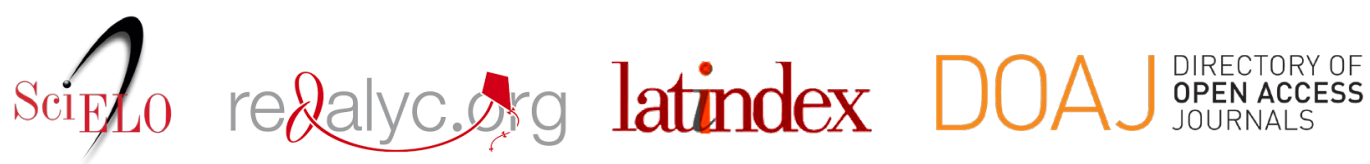

Distribuida en las bases de datos:

- Dialnet

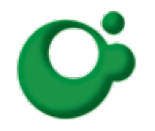
SHERPA/RoMEO

REDIB

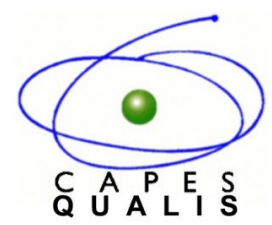

MIAR 